TABLE I. Depolarization cross sections and mean reorientation angles averaged over all rotational states for $\mathrm{I}_{2}{ }^{*}-\mathrm{M}$ collisions.

\begin{tabular}{|c|c|c|c|c|c|}
\hline \multirow[b]{2}{*}{$\mathbf{M}$} & \multicolumn{5}{|c|}{$\sigma_{\mathrm{pol}^{2}}\left(\mathrm{~cm}^{2} \times 10^{10}\right)$} \\
\hline & $\begin{array}{l}\Delta v^{\prime}=0 \\
\left(\text { all } J^{\prime}\right)\end{array}$ & $\begin{array}{c}\Delta v^{\prime}=0 \\
\left(\Delta J^{\prime} \neq 0\right)\end{array}$ & $\Delta v^{\prime}=+1$ & $\Delta v^{\prime}=-1$ & $\left\langle\frac{3}{2} \sin ^{2} \alpha\right\rangle_{J^{\prime}}$ \\
\hline $\mathbf{H}_{2}$ & 2.9 & 5.3 & $\cdots$ & $\cdots$ & 0.70 \\
\hline $\mathrm{He}$ & 3.7 & 7.0 & 12.9 & 9.4 & 0.74 \\
\hline $\mathrm{Ne}$ & 22.7 & 22.8 & $\cdots$ & $\cdots$ & 0.88 \\
\hline
\end{tabular}

observed depolarizations are greater for $\Delta v^{\prime} \neq 0$ than for $\Delta v^{\prime}=0$, it is also true that there is greater rotational energy transfer accompanying vibrationally inelastic collisions. Using the $\mathrm{known}^{\mathbf{s}} \Delta J^{\prime}$ distributions for $\Delta v^{\prime}= \pm 1$ collisions, and the $\left(\Delta J^{\prime} \neq 0\right)$ depolarization cross section already found, we can calculate an effective $\sigma_{\mathrm{pol}}{ }^{2}=(9-10) \times 10^{-16} \mathrm{~cm}^{2}$ for $\Delta v^{\prime}= \pm 1$. Thus, it appears that the observed depolarization may arise solely from the change in rotational state, and not reflect any significantly greater degree of reorientation of the molecular angular momentum accompanying the presumably "stronger" vibrationally inelastic collisions.

We would like to thank Ms. Andrea Sanders for her assistance with the data analysis, and Professor George Leroi of Michigan State University for the use of his experimental facilities and for comments on the initial draft of this Note. This work was supported by the National Science Foundation and the Petroleum Research Fund.

I R. L. Brown and W. Klemperer, J. Chem. Phys. 41, 3072 (1964).

2 J. I. Steinfeld and W. Klemperer, J. Chem. Phys. 42, 3475 (1965).

' R. B. Kurzel and J. I. Steinfeld, J. Chem. Phys. 53, 3293 (1970).

1J. I. Steinfeld and A. N. Schweid, J. Chem. Phys. 53, 3304 (1970).

B R. B. Kurzel, J. I. Steinfeld, D. A. Hatzenbuhler, and G. Leroi, J. Chem. Phys. 55, 4822 (1971).

- R. B. Kurzel, E. O. Degenkolb, and J. I. Steinfeld, J. Chem. Phys. 56, 1784 (1972).

'S. Mrozowski, Bull. Intern. Cracow 346 (1933); 295 (1937); P. Pringsheim, Fluorescence and Phosphorescence (Interscience, New York, 1948), p. 217.

J. I. Steinfeld, $\mathrm{Ph} . \mathrm{D}$. thesis, Harvard University, 1965.

' R. Gordon, J. Chem. Phys. 45, 1643 (1966).

THE JOURNAL OF CHEMICAL PHYSICS

VOLUME 56, NUMBER 10

\title{
Force Constants of the Metaborate Ion in Alkali Halides*
}

\author{
J. C. Decius, C. R. Becker, $\dagger$ and W. J. Fredericks \\ Department of Chemistry, Oregon State University, Corvallis, Oregon 97331
}

(Received 27 December 1971)

Previous infrared studies ${ }^{1}$ of the metaborate ion as a substitutional impurity in alkali halide lattices have yielded generally concordant values for the bending and antisymmetric stretching fundamental frequencies as well as the strongest combination mode which is the Fermi doublet $\nu_{1}+\nu_{3}$ and $2 \nu_{2}+\nu_{3}$. Isotopic species reported include ${ }^{10} \mathrm{~B}^{16} \mathrm{O}_{2}-{ }^{11} \mathrm{~B}^{16} \mathrm{O}_{2}-$.

The cyanate ion in similar hosts exhibits a splitting of the $\nu_{1}+\nu_{3}$ and $2 \nu_{2}+\nu_{3}$ doublet which is almost identical with the splitting of $\nu_{1}$ and $2 \nu_{2}$ which are observable for the unsymmetric linear triatomic molecule, but forbidden in the infrared spectrum of metaborate. In cyanate, the sums of the observed values of $\nu_{3}$ and of either of the observed values of the $\nu_{1}, 2 \nu_{2}$ doublet are about $20 \mathrm{~cm}^{-1}$ greater than the respective members of the $\nu_{1}+\nu_{3}, 2 \nu_{2}+\nu_{3}$ doublet. By transferring this anharmonicity correction from cyanate to metaborate we can predict the positions of the infrared inactive $\nu_{1}$,
$2 \nu_{2}$ frequencies as follows ( $\mathrm{KBr}$ host):

(i) ${ }^{10} \mathrm{~B}^{16} \mathrm{O}_{2}^{-}$:

$$
\begin{aligned}
\left(2 \nu_{2}+\nu_{3}\right)-\nu_{3}+20 & =3251-2029+20=1242 \mathrm{~cm}^{-1} \\
\left(\nu_{1}+\nu_{3}\right)-\nu_{3}+20 & =3095-2029+20=1086 \mathrm{~cm}^{-1}
\end{aligned}
$$

(ii) ${ }^{11} \mathrm{~B}^{16} \mathrm{O}_{2}^{-}$:

$$
\begin{aligned}
& \left(2 \nu_{2}+\nu_{8}\right)-\nu_{3}+20=3145-1958+20=1207 \mathrm{~cm}^{-1}, \\
& \left(\nu_{1}+\nu_{3}\right)-\nu_{3}+20=3022-1958+20=1084 \mathrm{~cm}^{-1}
\end{aligned}
$$

With the search area for these previously unknown energy levels rather narrowly circumscribed, we proceeded to examine the $\nu_{2}$ region of the spectrum of single crystals of $\mathrm{KBr}$ and $\mathrm{KCl}$ doped with metaborate in order to find the difference frequencies (hot bands) for the transitions $01^{\prime} 0 \rightarrow 10^{\circ} 0$ and $01^{\prime} 0 \rightarrow 02^{\circ} 0$ which 
Table I. New transitions and energy levels of metaborate ion in alkali halide hosts $\left(T=305^{\circ} \mathrm{K}\right)$.

\begin{tabular}{|c|c|c|c|c|c|}
\hline \multirow{2}{*}{$\begin{array}{l}\text { Initial } \\
\text { state }\end{array}$} & \multirow{2}{*}{$\begin{array}{l}\text { Final } \\
\text { state }\end{array}$} & \multicolumn{2}{|c|}{$\mathbf{K B r}$} & \multicolumn{2}{|c|}{$\mathrm{KCl}$} \\
\hline & & ${ }^{11} \mathrm{BO}_{2}^{-}$ & ${ }^{10} \mathrm{BO}_{2}^{-}$ & ${ }^{1} \mathrm{BO}_{2}^{-}$ & ${ }^{10} \mathrm{BO}_{2}^{-}$ \\
\hline $00^{\circ} 0$ & $02^{\circ} 1$ & 3145 & 3251 & 3163 & \\
\hline $00^{\circ} 0$ & $10^{\circ} 1$ & 3023 & 3095 & 3042 & \\
\hline $00^{\circ} 0$ & $01^{\prime} 0$ & 588.6 & 609.5 & 589.5 & \\
\hline $01^{\prime} 0$ & $02^{\circ} 0$ & 613.5 & 631.5 & 617 & \\
\hline $01^{\prime} 0$ & $10^{\circ} 0$ & 490 & 474 & 495 & \\
\hline \multirow[t]{2}{*}{$00^{\circ} 0$} & $02^{\circ} 0$ & $(1202.1)$ & (1241) & $(1206.5)$ & \\
\hline & & $1203^{a}$ & & & $1244^{*}$ \\
\hline \multirow[t]{2}{*}{$00^{\circ} 0$} & $10^{\circ} 0$ & $(1078.6)$ & $(1083.5)$ & $(1084.5)$ & \\
\hline & & 1079s & & & $1090^{\circ}$ \\
\hline \multicolumn{2}{|c|}{$\nu_{1}$ (unperturbed) } & 1103.5 & 1105.5 & 1112 & 1112 \\
\hline
\end{tabular}

- All frequencies are observed in the infrared spectrum except these marked "w", which were observed in the Raman effect, and those enclosed in parentheses, which were calculated using the Ritz principle.

are infrared allowed and have been detected in cyanate studies. ${ }^{2}$ The results are summarized in Table I which includes some previously unreported data on the combination bands and which gives also the calculated positions of $\nu_{1}$ and $2 \nu_{2}$ which, since they are obtained by the Ritz principle, involve no assumptions about anharmonicity; it is seen that the results found are in good agreement with the prediction based upon the transferred anharmonicity correction.

Subsequent to the infrared studies which have just been described, we were able to observe several of the crystal samples with Laser excited Raman techniques. The lines found in this way are also reported in Table I. The intensity ratio for this Fermi doublet is approximately 2.5 to 1 for ${ }^{11} \mathrm{BO}_{2}^{-}$and 3.3 to 1 for ${ }^{10} \mathrm{BO}_{2}^{-}$, the lower frequency in each case being stronger. By neglecting the effects of anharmonicity except via the Fermi resonance, we have estimated the unperturbed value of $\nu_{1}$ as shown in the last line of the table. Since sufficient levels of metaborate are not yet known to correct for anharmonicity, we have calculated the force constants using the observed values of $\nu_{1}$ given in the table together with previously reported ${ }^{1}$ values for $\nu_{3}$. The BO stretching constant turns out to be $f_{\mathrm{BO}}=$ $11.4 \mathrm{mdyn} / \AA$ and the interaction constant is $f^{\prime}=2.2$ mdyn $/ \AA$ ( $\mathrm{KBr}$ host). Similar calculation of the force constants of the isoelectronic molecules $\mathrm{CO}_{2}$ and $\mathrm{NO}_{2}{ }^{+3}$ yields for $f_{\mathrm{CO}}=15.5$ and $d_{\mathrm{NO}}=17.3 \mathrm{mdyn} / \AA$. Although the spectroscopic measurements come from different phases for the isoelectronic sequence $\mathrm{BO}_{2}^{-}$, $\mathrm{CO}_{2}, \mathrm{NO}_{2}{ }^{+}$, the trend of increasing bond strength with increasing nuclear charge of the central atom is clear. It may also be of interest to note that the value of $\nu_{1}=1104.5$ ( $\mathrm{KBr}$ average) is found to be larger than $\nu_{1}=1070^{4}$ in the neutral $\mathrm{BO}_{2}$, just as $\nu_{1}=1335$ (average of Fermi doublet) in $\mathrm{CO}_{2}$ is greater than $\nu_{1}=1280$ in $\mathrm{CO}_{2}+{ }^{5}$

Thanks are due to Dr. J. Willis of the Cary Instrument Company and to Mr. Bob Reed of Spex Industries for having demonstrated the feasibility of detecting the Raman modes.

\footnotetext{
* Research supported by the National Science Foundation under grants GP-6893 and GP-8051 and based on a portion of a thesis submitted in partial fulfillment of the requirements for the degree of Doctor of Philosophy.

† Present address: Physikalisches Institute der Universitat 87 Würzberg, Röntgenring 8 , Germany.

1 R. S. McDonald, Spectrochim. Acta 15, 773 (1959). H. W. Morgan and P. A. Staats, J. Appl. Phys. 33, 364 (1962).

${ }^{2}$ Arthur Maki and J. C. Decius, J. Chem. Phys. 31, 772 (1959). V. Schettino and I. C. Hisatsune, ibid. 52, 9 (1970).

${ }^{3}$ Roy Teranishi and J. C. Decius, J. Chem. Phys. 22, 896 (1954).

' J. W. C. Johns, Can. J. Phys. 39, 1738 (1963).

s. W. C. Johns, Can. J. Phys. 42, 1004 (1964).
}

\section{Raman Spectroscopy, Rotational Isomerism, and the "Rotator" Phase Transition in $n$-Alkanes}

J. D. Barnes and B. M. Fanconi

National Bureau of Standards, Washington, D. C. 20234

(Received 13 January 1972)

Many $n$-alkanes exhibit a first-order solid-solid phase transition a few degrees below their melting points. The earliest molecular interpretation of this phenomenon was given by Muller $^{1}$ and later studies ${ }^{2}$ have tended to reinforce his view that the phase transition is associated with the onset of hindered rotation of the extended alkane chains about their long axes. Recently Pechold and his co-workers ${ }^{3-6}$ have proposed a "kinkblock" model in which the phase transition is associated with the occurrence of rotational isomers belonging to a particular class, the so-called kinkisomers. Since the $n$-alkanes and their polar derivatives 